\title{
Indicações geográficas, capital social e desenvolvimento territorial
}

\author{
Flavio Sacco dos Anjos \\ Universidade Federal de Pelotas - Pelotas - RS - Brasil \\ ORCID: https://orcid.org/0000-0002-0582-7627 \\ Fernanda Novo da Silva \\ Universidade Federal de Pelotas - Pelotas - RS - Brasil \\ ORCID: https://orcid.org/0000-0002-0582-7627 \\ Nádia Velleda Caldas \\ Universidade Federal de Pelotas - Pelotas - RS - Brasil \\ ORCID: http://orcid.org/0000-0002-0303-0681
}

\begin{abstract}
Resumo
Esse artigo aborda a questão da construção dos sinais distintivos de mercado, mormente das indicações geográficas de produtos agroalimentares como um instrumento para o desenvolvimento dos territórios e/ou das regiões essencialmente rurais. A abordagem leva em conta duas experiências relativas ao estado do Rio Grande do Sul a partir de uma análise comparativa que expõe seus respectivos avanços e debilidades. A pesquisa baseou-se em entrevistas realizadas entre os anos 2008 e 2012 com diversos atores sociais ligados a ambas as iniciativas. $O$ estudo mostra que isoladamente tais dispositivos não são suficientes para a ampliação dos horizontes em regiões marcadas por uma racionalidade individualista e pouco aberta à cooperação.
\end{abstract}

Palavras-chaves: Indicações geográficas. Capital social. Desenvolvimento territorial.

\section{Abstract}

\section{Geographical indications, social capital and territorial development}

This article addresses the question of the construction of distinctive market signals, particularly the geographical indications of agri-food products as an instrument for the development of essentially rural territories and / or regions. The approach takes into account two experiences regarding the state of Rio Grande do Sul from a comparative analysis that exposes their respective advances and weaknesses. The research was based on interviews conducted between 2008 and 2012 with various social actors linked to both initiatives. The study shows that these devices alone are not enough to widen horizons in regions marked by an individualistic rationality and little open to cooperation.

Keywords: Geographical indications. Social capital. Territorial development. 


\section{Resumen}

\section{Indicaciones geográficas, capital social y desarrollo territorial}

El presente artículo aborda la cuestión de la construcción de signos distintivos de mercado, en especial de las indicaciones geográficas de productos agroalimentarios como un instrumento para el desarrollo de los territorios y/o de las regiones esencialmente rurales. El abordaje se basa en dos experiencias relativas al estado de Rio Grande do Sul a partir de un análisis comparativo que expone sus respectivos avances y debilidades. La investigación se basa en entrevistas llevadas a cabo entre los años 2008 e 2012 con distintos actores sociales ligados a ambas iniciativas. El estudio muestra que aisladamente tales dispositivos no son suficientes para la ampliación de los horizontes en regiones en las que predomina una racionalidad individualista y poco abierta a la cooperación.

Palabras clave: Indicaciones geográficas. Capital social. Desarrollo territorial.

\section{Introdução}

A construção de itinerários de qualidade na produção agroalimentar tem sido apontada como uma forma de fomentar o desenvolvimento de territórios rurais, seguindo a experiência recente das políticas levadas a efeito nos países da União Europeia pela via do fomento à inovação, à coesão e cooperação dos atores sociais. Por conta disso, os sinais distintivos de mercado (produtos tradicionais, indicações geográficas, produtos ecológicos, etc.) são vistos como elementos catalizadores de processos de transformação e de diversificação da matriz produtiva.

O presente estudo trata de analisar essa questão a partir de uma abordagem comparativa de dois processos de valorização da origem e da qualidade de produtos agroalimentares, quais sejam, as indicações geográficas da carne do Pampa da Campanha Meridional e dos vinhos do Vale dos Vinhedos. Na realização da pesquisa interessava-nos abordar, no cotejo de ambas as realidades, porque alguns territórios convertem-se em terreno fértil para a inovação, enquanto outros enfrentam limites e obstáculos na ampliação dos próprios horizontes. A primeira seção discute o que consideramos como as duas principais ferramentas de análise de processos desse gênero, ao passo que as seções subsequentes abordam os dois casos em questão. A última seção reúne as considerações finais deste estudo.

\section{A abordagem territorial e capital social}

A abordagem territorial surge, dentre outros aspectos, a partir do reconhecimento de que desenvolvimento agrícola e desenvolvimento rural não podem ser assumidos como noções necessariamente coincidentes, tal como antes se supunha. A realidade de nosso país demonstra, de forma cabal, que ambos os termos podem inclusive conduzir, paradoxalmente, a caminhos absolutamente antagônicos. Durante muito tempo admitiu-se que a incorporação de novas tecnologias levaria a um incremento geral das rendas agrícolas e, consequentemente, à melhoria das condições de vida e de trabalho no espaço rural. Passadas algumas décadas, desde o auge da modernização conservadora (GUIMARÃES, 1978), também chamada de modernização dolorosa (GRAZIANO DA 
SILVA, 1982), são evidentes os sinais que indicam a insuficiência destes pressupostos.

Sob a égide do modo de produção capitalista, e no afã de rentabilizar os ativos agrários, se impôs uma visão na qual o desenvolvimento agrícola pressupunha ocupar o mínimo de mão-de-obra, assegurando níveis crescentes de lucro para a atividade agropecuária. Em suma, durante muito tempo admitia-se que fazer 'desenvolvimento agrícola' era produzir muito e com muito pouca gente. Hoje, entretanto, reconhecemos que pensar em desenvolvimento rural, sem a presença das pessoas, das comunidades e das instituições a que elas pertencem é totalmente infundado.

Há, no limite, pelo menos três grandes vícios de origem na concepção que convencionalmente guiou a atuação do Estado brasileiro no âmbito do desenvolvimento rural. O primeiro deles recai no 'viés setorial', que reduz toda a discussão sobre os desafios do desenvolvimento ao marco estrito do apoio a cadeias produtivas ou a setores específicos da atividade agropecuária, alimentando a ilusão de que todo esse esforço pudesse se espraiar sobre o tecido social das áreas rurais e das pequenas localidades.

O segundo vício de origem, parafraseando Favareto (2007, p. 14), é o viés do 'combate à pobreza rural', cuja natureza reflete os anseios do Estado brasileiro em ampliar as fontes de legitimidade de sua atuação, vinculando-a ao âmbito estrito do combate a esse grave problema social. Por mais meritória que seja essa missão, não cabe dúvida de que enfrentar os desafios do desenvolvimento requer muito mais do que isso. Implica construir alianças estratégicas e consolidar pactos territoriais de longo prazo no combate às desigualdades espaciais. O balanço geral que fazemos, frente a essa questão, expõe duas grandes lições: a primeira delas, com perdão da redundância, é no sentido de conceber políticas 'pobres' (de conteúdo) para os pobres. A segunda lição é insistir nos velhos esquemas de caráter assistencialista e tutelar.

Já o terceiro vício de origem tem a ver com as transformações decorrentes da nova Constituição brasileira (1988) e das mudanças no ordenamento político e institucional que convergiram para a transferência de diversas competências da União para a órbita dos municípios. Mas se os problemas atinentes à municipalização já são bastante conhecidos, mais graves são os efeitos atinentes ao que se veio a chamar de "prefeiturização" (SACCO DOS ANJOS; CALDAS, 2007, p. 665), notadamente a velha tendência de concentrar, no poder público municipal, a solução para os problemas locais, numa eterna disputa por recursos, invariavelmente escassos, com outras prefeituras da região, em lugar de estabelecer pactos e fomentar sinergias em torno a objetivos mais amplos à escala territorial.

O que aqui se quer afirmar, em última análise, é que a abordagem territorial, que serve de fonte inspiradora para as propostas de intervenção das agências nacionais e internacionais de desenvolvimento (especialmente a FAO, IICA, CEPAL, OCDE), surge, entre outros aspectos, como um esforço de ultrapassar os limites impostos por estes três vícios de origem da atuação estatal e dos órgãos de cooperação e fomento. Esta tem sido a tônica de alguns estudos (VEIGA, 2000; ABRAMOVAY, 2003; FAVARETO, 2007; ANJOS, 2003) realizados recentemente no 
Brasil, os quais, em linhas gerais, reivindicam um novo olhar para os espaços rurais e para as regiões não densamente urbanizadas.

Todavia, como advertiu Favareto (2010), longe estamos de operar essa "mudança de paradigma" no sentido de alterar um padrão que segue sendo absolutamente dominante. Convergimos com esse entendimento, sobretudo quando o citado autor afirma que:

[...] a introdução do adjetivo "territorial" no repertório das organizações não governamentais, da burocracia estatal e dos movimentos sociais é marcada pelos limites de uma incorporação 'por adição' [...] e não como um sinal de mudança institucional." (FAVARETO, 2010, p. 314; aspas no original).

Não é preciso muito esforço para mostrar quão fortes são as amarras que nos prendem ao que Hervieu (1996, p. 105) definiu como "fundamentalismo agrário" ao comentar a trajetória da política agrária dos países que atualmente integram a União Europeia, seguindo a senda do desenvolvimento agrícola. A preocupação em torno ao despovoamento das áreas rurais e o destino das regiões deprimidas serviu de base para o surgimento de um novo marco de intervenção nos países pertencentes ao velho continente, como é precisamente o caso do LEADER ${ }^{1}$.

$\mathrm{Na}$ acepção clássica do geógrafo francês, já consagrada no jargão das agências de desenvolvimento, 'são os projetos que moldam os territórios' (KAYSER et al, 1994). Sob esse prisma, parece evidente que o território não pode ser visto como algo dado ou imutável. O que estes estudos reafirmam, de modo peremptório, é que o território pressupõe interação social, além de ser fonte de conhecimento, "de geração e difusão de inovação" (ORTEGA; JEZIORNY, 2011, p. 113). Não pode, portanto, ser definido pelo estoque de recursos materiais existentes em seu interior, mas sim, pela maneira como os atores sociais e as instituições se organizam em torno a modelos mentais partilhados.

\subsection{0 capital social dos territórios}

São surpreendentes as diferenças entre determinadas zonas da geografia brasileira do ponto de vista dos índices de desenvolvimento, da distribuição de renda ou mesmo do ambiente institucional requerido para incitar processos de inovação. Para além dos efeitos engendrados pela conhecida incapacidade de operar mudanças estruturais imprescindíveis (ampliação do acesso à terra, à tecnologia, aos bens públicos, etc.), existem outros fatores que jogam um papel decisivo para conformar essa realidade.

Quando se alude ao capital social dos territórios busca-se romper - como advertiu Abramovay (2003, p. 86), citando Coleman (1990) - com um dos mitos fundadores da civilização moderna, no sentido de entender que a sociedade é um

\footnotetext{
${ }^{1}$ LEADER é o nome dados às sucessivas iniciativas de desenvolvimento rural da União Europeia. Corresponde à sigla "Liaisons entre activités de Development de L'Economie Rural". Na edição correspondente ao Leader Plus (2000-2006) há uma ênfase especial no desenvolvimento de quatro grandes temas: a) utilização de novos conhecimentos e tecnologias, b) melhoria da qualidade de vida, c) valorização dos produtos locais; d) valorização dos recursos naturais e culturais, como é precisamente o caso das indicações geográficas de produtos agroalimentares.
} 
conjunto de indivíduos agindo isoladamente para atingir objetivos a que chegam independentemente uns dos outros.

A importância dessa ferramenta interpretativa ganha uma dimensão considerável a partir dos estudos de Putnam, surgidos ao longo dos anos 1990, cujo foco esteve dirigido a examinar as diferenças de desempenho econômico e institucional entre as regiões italianas. Suas investigações mostram que as zonas setentrionais deste país ostentam padrões e sistemas dinâmicos de engajamento cívico, cujos cidadãos são atuantes, dotados de espírito público e onde as relações políticas são predominantemente igualitárias. Uma região em que a estrutura social descansa, firmemente, sobre um sentimento de confiança e colaboração. No extremo oposto, nas zonas que conformam a Itália meridional, a situação é diametralmente oposta. A vida social se baseia no isolamento, na falta de integração, em meio a uma cultura regida pela desconfiança, pela quase total ausência de valores cívicos, bem como por uma estrutura política verticalmente estruturada.

Mark Granovetter $(1985 ; 1990)$ é outro autor que se debruçou sobre o tema do capital social. Em seus trabalhos, insiste no fato de que a ação econômica é socialmente situada, que os indivíduos não agem de maneira autônoma e que suas ações estão imbricadas em sistemas concretos e contínuos de relações sociais que conformam redes, traduzidas num termo - embeddedness ${ }^{2}$ - já consagrado no jargão acadêmico brasileiro e mundial. Granovetter (1990) estabelece dois tipos de imbricação: o relacional e o estrutural. O primeiro deles, diz respeito às relações pessoais, ou seja, às relações mais próximas dos indivíduos (família, amigos, etc.), também definidas como "laços fortes". Já o segundo tipo compreende as relações mais afastadas, as quais o indivíduo tem acesso graças aos seus laços fortes, mas que o colocam em contato, através de "laços fracos", com universos sociais distintos.

Considerado como um dos fundadores da nova sociologia econômica, Granovetter (1973), argumenta, em um trabalho que se tornou célebre (The strength of weak ties), que a força está justamente nos laços fracos porque são eles os responsáveis por expandir os horizontes, abrindo espaço para os processos de inovação e de aprendizagem no âmbito dos territórios. Num país multicultural e de dimensões continentais, como é o Brasil, marcado por diferenças abissais entre as grandes regiões e seus territórios, não causa estranheza a rapidez com que o capital social se converteu numa espécie de farol acionado para iluminar todo um debate, que no limite, extrapola os cânones estritos da perspectiva acadêmica.

O capital social, como ponderou Abramovay (2003), corresponde ao ethos de uma certa sociedade e, no nosso entendimento, a uma identidade moldada a partir de um conjunto de valores compartilhados, os quais não são transferíveis de um contexto para outro. Isso é crucial, sobretudo quando pensamos em valores simbólicos, a exemplo da disposição para a cooperação em torno à criação de um novo sujeito coletivo que não pode estar restrito a uma empresa, a um setor ou

\footnotetext{
${ }^{2}$ Como refere Machado (2010), Karl Polany, em sua obra seminal (A grande transformação), é quase consensualmente considerado como o sendo o pai do conceito em tela, traduzido para o português como incrustação ou também enraizamento, mostrando que as ações econômicas dos indivíduos estão sempre inseridas em redes de relações sociais.
} 
cadeia produtiva, mas sim a uma capacidade de articulação que faça aflorar as forças produtivas de um território em torno a uma determinada ideia-guia.

Em resumidas contas, a ideia de capital social reflete a natureza de um conceito polissêmico, bem como a inexistência de uma acepção única no âmbito das ciências humanas e sociais aplicadas. Nesse trabalho adotamos como base a contribuição de Garrido \& Moyano, segundo a qual,

[...] esta nova forma de capital inclui determinados tipos de normas,
valores e crenças (como a confiança entre vizinhos, o respeito à palavra
dada ou a credibilidade das instituições), assim como de redes sociais (daí
que também se costume chamar "capital relacional"), os quais, segundo
dessa perspectiva teórica, são importantes para o desenvolvimento,
justamente porque favorecem a realização de ações coletivas em
benefício da própria comunidade (GARRIDO \& MOYANO, 2002, p.70;
destaques no original).

A criação de indicações geográficas, de que nos ocuparemos nesse artigo científico, se insere justamente no centro desse debate. Sob a égide do processo de globalização, e de um ambiente cada vez mais competitivo, reduzem-se sensivelmente as distâncias, fazendo com que produtos elaborados a milhares de quilômetros inundem as gôndolas das pequenas e grandes superfícies de varejo. Para muitas empresas e para os territórios resta o caminho da busca de vantagens competitivas que ultrapassem a mera concorrência por preços e/ou uso de insumos baratos. Esse é precisamente o caso das indicações geográficas e do conjunto de signos distintivos de mercado de produtos agroalimentares que valorizam a singularidade dos processos e/ou dos locais em que foram obtidos.

\section{Indicações geográficas e desenvolvimento territorial: entre mitos e realidades}

Nossa reflexão, que explora as interfaces entre indicações geográficas e desenvolvimento territorial, pauta-se na análise de duas experiências referenciais existentes no Rio Grande do Sul (ver Fig. 1). O material de análise foi colhido em 26 entrevistas realizadas, de modo intermitente, entre os anos 2008 e 2012, com diferentes atores sociais (representantes de empresas, de Conselhos Reguladores, associações de produtores, extensionistas rurais, agricultores, etc. $)^{3}$.

As duas indicações geográficas respondem ao apelo da diferenciação sob um cenário cada vez mais competitivo. Não obstante, guardam elas enormes diferenças do ponto de vista dos arranjos institucionais e do capital social correspondente a estes dois territórios, com todas as suas especificidades e idiossincrasias.

Figura 1 - Mapa ilustrativo dos municípios que integram as Indicações Geográficas "Vale dos Vinhedos" (IPVV) e "Carne do Pampa Gaúcho da Campanha Meridional" (IPCPG)

\footnotetext{
${ }^{3}$ Os entrevistados foram indicados por atores chaves diretamente implicados na construção das duas indicações geográficas, os quais livremente aceitaram responder as questões propostas no roteiro semiestruturado que continha questões abertas e fechadas. Os depoimentos foram integralmente transcritos, sendo o processo de inferência baseado na técnica da análise de conteúdo.
} 


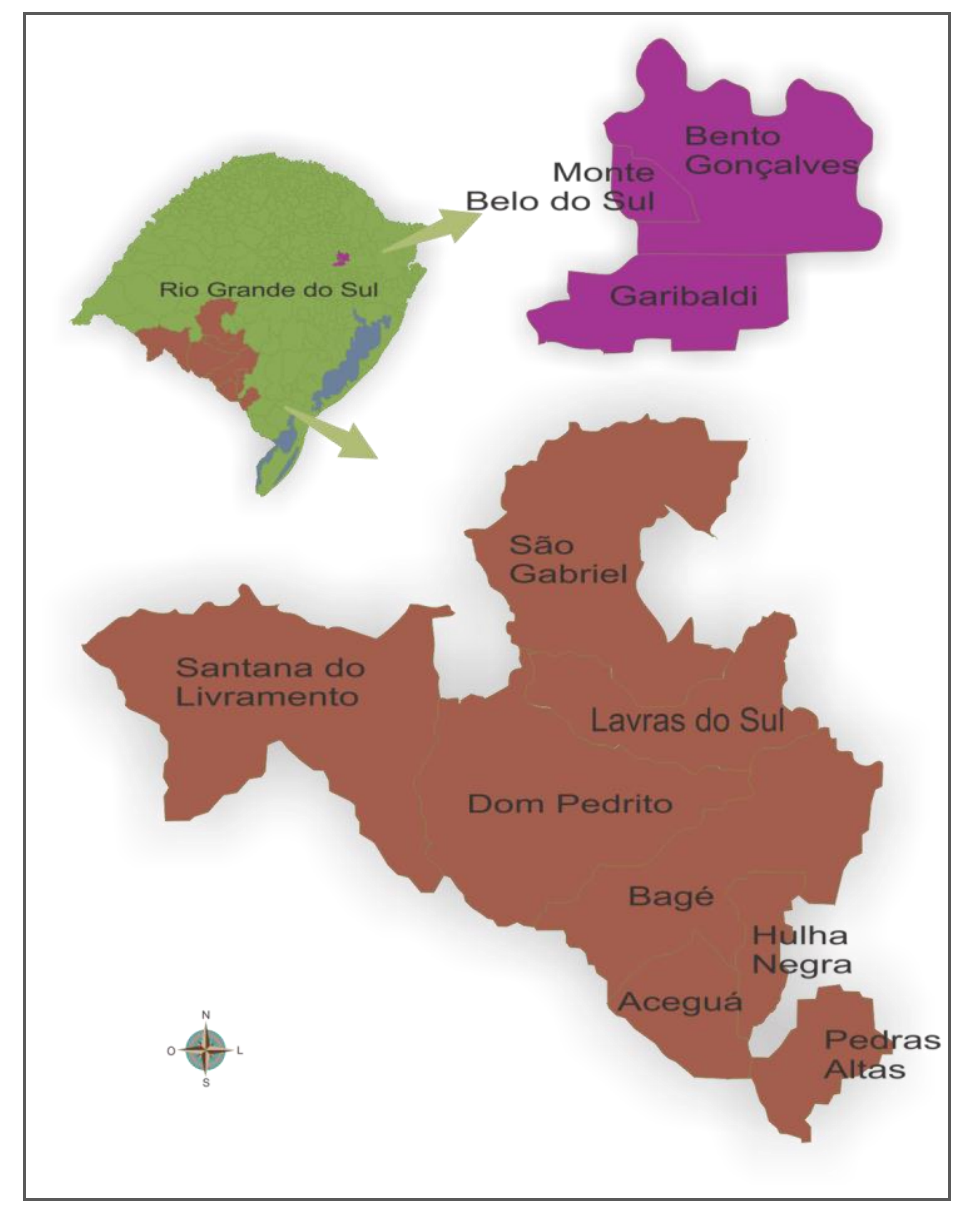

Fonte: Elaboração dos autores (2012)

\subsection{Vinhos e espumantes do Vale dos Vinhedos}

É impossível falar de indicações geográficas no Brasil sem mencionar o caso do Vale dos Vinhedos. Não somente porque foi esta a primeira Indicação de Procedência (doravante IPVV) surgida em nosso país, mas porque se tornou uma referência em que se apoiaram todas as demais iniciativas do gênero surgidas no Brasil. Examinemos as suas peculiaridades.

O processo de colonização levado a cabo no Rio Grande do Sul, durante a primeira e a segunda metade do século XIX, exerceu enorme influência na conformação atual dessa unidade federativa. Nesse sentido, para o argumento central desse estudo importa destacar dois grandes efeitos desse processo, quais sejam: o de contribuir para a constituição de um dos mais importantes setores da agricultura familiar ${ }^{4}$ nacional e, por outra parte, o de assentar as bases para consolidar a indústria regional.

Tais efeitos estiveram estreitamente ligados ao protagonismo exercido pelos colonos procedentes da Europa (alemães, italianos, poloneses), os quais incorporaram à sociedade gaúcha um ethos singular (GAIGER, 1994; TEDESCO, 1999)

\footnotetext{
4 Tal importância reside não exatamente no número de produtores identificados com estas características, que somam 400 mil estabelecimentos rurais nesta unidade federativa brasileira, mas sobretudo pelo conhecido dinamismo e presença nos mercados nacionais e estrangeiros, a exemplo das grandes cadeias de produtos de exportação (tabaco, soja, carnes e derivados, hortifrutícolas, etc.).
} 
que expressa os traços típicos do campesinato centro-europeu, principalmente seu dinamismo para a diversificação das atividades. Os analistas coincidem no entendimento de que as raízes da industrialização das zonas setentrionais desse Estado encontram-se precisamente associadas ao florescimento desta "agricultura colonial" e ao processo de acumulação de riqueza daí resultante, um fenômeno no qual foi muito importante o conhecimento técnico destes imigrantes.

Some-se a isso a intensa articulação que se foi desenvolvendo entre os interesses expansionistas de certos ramos de atividade fabril (metalúrgicas, têxteis, calçados, vinhos, etc.) e as estratégias próprias das famílias rurais para garantir sua reprodução social, conferindo à dinâmica social e econômica destes territórios um traço diferencial frente a outras regiões do país e, inclusive, do próprio Rio Grande do Sul.

Para os objetivos desse artigo vale destacar outra faceta deste cenário e que se associa à trajetória da imigração italiana numa região precisa deste Estado, qual seja, a chamada Serra Gaúcha, conhecida como um importante destino turístico do Brasil meridional onde se produz atualmente $90 \%$ da produção nacional de vinhos (GOLLO, 2006). E é precisamente no interior dessa região que se encontra a primeira experiência de indicação geográfica do Brasil. A trajetória que acompanhou essa iniciativa não pode ser descrita sem aludir ao papel desempenhado pelos italianos que desembarcaram no Estado, em 1875.

Até o início do século $\mathrm{XX}$, o vinho era produzido com o fito de atender fundamentalmente ao consumo próprio das famílias, utilizando-se variedades rústicas de uva. Mas a partir das décadas de 1970 e 1980 a região ingressa numa outra etapa da vitivinicultura com o aporte de capital internacional e a busca de aperfeiçoamento nos sistemas de produção, processo este impulsionado pela ampliação do mercado interno, cada vez mais aberto ao consumo de vinhos de melhor qualidade. Nessa época o Brasil adota uma política de incremento da qualidade centrada nos chamados "vinhos varietais". Todavia, como afirma Tonietto (2006) são vinhos cujo elemento de destaque não é a região produtora, mas a variedade da uva usada em sua elaboração.

O período subsequente coincide com uma série de mudanças, entre as quais figura a criação do Mercosul e os efeitos que esse fato engendra sobre o setor vitivinícola nacional face o ingresso dos vinhos procedentes do Uruguai e, particularmente, do Chile e da Argentina, que entram em nosso país sob condições tarifárias que promovem uma feroz competência com o produto nacional. É justamente no rastro destas questões que se deve entender não somente a criação da Associação dos Produtores de Vinhos Finos do Vale dos Vinhedos (Aprovale), mas de um conjunto de iniciativas centradas tanto no objetivo de demonstrar 0 "efeito terroir" desta região sobre os vinhos elaborados, mas de defender os interesses do setor.

Desse modo, o Brasil ingressa, como afirma Tonietto (2006), na produção dos vinhos de "quarta geração", que devem afirmar a identidade e qualidade do produto nacional, seja no plano do mercado interno que se enfrenta à aludida competência do artigo importado, seja no plano do leque de oportunidades que brindam os mercados internacionais.

A estratégia adotada culminou na conquista da Indicação de Procedência em 2002, através da qual se procedeu à adoção de critérios de delimitação geográfica e 
criação de um Conselho Regulador. Esta IP abarca uma superfície de $81,23 \mathrm{~km}^{2}$ e se distribui por três municípios (Bento Gonçalves, Garibaldi e Monte Belo do Sul). Os produtos protegidos são os vinhos tintos, brancos e espumantes, havendo um conjunto de rigorosos procedimentos que devem ser cumpridos para que os mesmos carreguem a alcunha do "Vale dos Vinhedos". A Aprovale congrega atualmente 25 vinícolas, além de 40 outros associados que incluem hotéis, restaurantes, queijarias, pousadas e outras empresas.

A principal agência de pesquisa agrícola do Brasil (Embrapa) desempenhou um papel de destaque nesse processo, por meio do qual se buscava uma saída à crise produzida pelos vinhos estrangeiros. O principal agente articulador dessa iniciativa menciona este fator como elemento decisivo para induzir ao processo que culminou na formação da Aprovale, num primeiro momento, e, posteriormente na criação da IP. Segundo suas próprias palavras:

\begin{abstract}
O Vale dos Vinhedos é uma carta de apresentação, é um diferencial, contatar com o pessoal do Vale dos Vinhedos é um pessoal diferenciado. Isso aí ajuda a enfrentar esse mercado muito complicado, muito complicado. É um fator que tem ajudado, e essa é a ideia. Quando a gente começou a construir as indicações geográficas aqui no Brasil para vinhos, se sabia que o mercado ia abrir porque tem gente muito boa nesse mundão afora, as regiões são cada vez melhores, investindo. Sem qualidade não se consegue nada 5 .
\end{abstract}

Tal experiência gerou importantes efeitos, tanto interna quanto externamente à região. No primeiro caso há que mencionar os benefícios sobre os processos de produção vitivinícola, trazendo consigo a incorporação da rastreabilidade e de diversos mecanismos de controle da qualidade da uva e do vinho, mas também na perspectiva do fortalecimento de uma identidade regional calcada na alusão à história dos pioneiros e que se reflete no encanto de paisagens que incluem caminhos rurais, casarios de pedra e velhas cantinas, em meio a um cenário que muito se assemelha às regiões setentrionais da velha Itália.

O êxito verificado na iniciativa do Vale dos Vinhedos induziu a que nessa região fossem criadas outras associações de produtores imbuídas do mesmo objetivo, qual seja o da criação de uma IG, como é o caso da Aprobelo (Associação dos Vitivinicultores de Monte Belo do Sul), Afavin (Associação Farroupilhense de Vinicultores), Apromontes (Associação de Produtores dos Vinhos dos Altos Montes) e Asprovinho (Associação dos Produtores de Vinhos de Montanha). Tais associações encontram-se articuladas em torno a um ambicioso projeto nacional intitulado "Wines from Brazil" cujo grande objetivo é dar a conhecer, internacionalmente, a qualidade e singularidade dos vinhos do país, no qual há um alto nível de protagonismo desta zona situada no interior da Serra Gaúcha ${ }^{6}$.

Se nos fixamos no âmbito externo, há que mencionar que esta experiência contribuiu para impulsionar o florescimento de outras experiências de IG no Rio Grande do Sul (Carne do Pampa Meridional Gaúcho, Arroz do Litoral Norte e Couros

\footnotetext{
${ }^{5}$ Entrevista concedida em Bento Gonçalves, no dia 19 de abril de 2012.

${ }^{6}$ Entre as conquistas da Aprovale, há que mencionar o reconhecimento do Vale dos Vinhedos, em 2007, pela União Europeia, o que permitiu a exportação, nesse mesmo ano, de 435 mil litros de vinho, uma modesta quantidade que corresponde a $35 \%$ da produção certificada (NIEDERLE, 2009), mas interessante para acalentar o sonho de abertura de novos mercados.
} 
do Vale dos Sinos) e em outras regiões do país como é o caso da Cachaça do Brasil e do Café do Cerrado, apenas por citar alguns exemplos.

Entrementes, o Vale dos Vinhedos vivencia algumas dificuldades relacionadas ao esforço de conciliar os distintos interesses implicados (públicos e privados) e sedimentar as bases para uma estratégia territorial de longo prazo. Um dos grandes problemas resulta do protagonismo excessivo das grandes vinícolas em virtude do considerável peso econômico e político que lhes corresponde no plano local e regional. O contato com os atores que interagem nesse cenário detectou alguns discursos que se chocam frontalmente com as virtuosidades do "Vale dos Vinhedos".

Referimo-nos, especialmente, às organizações não-governamentais ligadas à produção ecológica que consideram que esta iniciativa reproduz os mesmos mecanismos de extração do sobretrabalho dos produtores familiares. Além disso, argumentam que há um claro desprestígio com relação à produção vitivinícola gerada através de variedades rústicas como no caso da cultivar Isabel, que apesar de produzir um vinho considerado de qualidade inferior, o sistema de produção que Ihe corresponde demanda uma carga bastante inferior de agrotóxicos, comparativamente ao das uvas finas ou viníferas.

Ainda assim, o balanço ${ }^{7}$ da iniciativa é muito positivo, particularmente por favorecer a emergência de uma série de empreendimentos cujo atrativo essencial reside no chamado "enoturismo". O conhecido empreendedorismo dos descendentes de italianos é, sem dúvida, a força essencial que impulsionou tais iniciativas, favorecendo a criação de pequenos negócios ligados, especialmente, à gastronomia e hotelaria.

\subsubsection{O Capital social do Vale dos Vinhedos}

No livro publicado por Ortega e Jeziorny (2011), dedicado a estudar a experiência relativa à IPVV, os autores concluem que as indicações geográficas e o território "formam uma espécie de simbiose, pois não existe indicação geográfica sem o território, ao passo em que o próprio território pode se desenvolver por meio da construção de uma indicação geográfica" (p. 149).

Coincidimos parcialmente com estas premissas e não foi outro motivo que especial atenção foi dada, neste trabalho, à abordagem territorial do desenvolvimento. Não obstante, nossa ressalva recai no entendimento de que a realidade, não raras vezes, evidencia a existência não de um, mas de vários projetos de natureza territorial, os quais podem convergir, mas também conflitar em termos de natureza, conteúdo, objetivos e efeitos. O fato é que há projetos que muitas das vezes exploram uma mesma narrativa, evocando aos mesmos valores, de uma identidade compartilhada, ou de uma mesma matriz cultural, como é precisamente o caso do que aqui denominamos "italianidade".

Feita essa ponderação, cabe agora analisar o caso da IPVV sob o prisma dessas vertentes interpretativas. Que aspectos são claramente perceptíveis para explicar o êxito desta iniciativa do ponto de vista do capital social ali presente? Não

\footnotetext{
7 Um dos grandes logros associados à iniciativa "Vale dos Vinhedos" está no sentido de mostrar a importância de frear o avanço do processo de urbanização sobre as áreas rurais, particularmente no município de Bento Gonçalves, através da criação de condomínios horizontais e loteamentos.
} 
é irrelevante dizer que a vitivinicultura representa um poderoso marcador de uma identidade forjada ao sabor das circunstâncias relativas à difícil adaptação dos pioneiros a uma terra inóspita, muito distante, decerto, do lugar mítico que seduziu muitos colonos a virem para o Brasil. Dificuldades estas que sedimentaram as bases para que aflorassem experiências associativas importantes ligadas ao mundo da uva e do vinho, mas também aos antigos moinhos coloniais.

A IPVV não pode ser vista simplesmente como uma mera ferramenta mercadológica de promoção de um produto de qualidade diferenciada, mas como um instrumento de desenvolvimento ancorado num território específico e que se nutre de uma herança cultural e histórica extremamente potente, em torno da qual outras iniciativas possam aflorar (o turismo, a gastronomia, a prestação de serviços, etc.).

Mas será que os resultados dessa construção capitaneada pela indicação geográfica fortalecem, efetivamente, a plenitude dos setores constituintes do tecido social e produtivo de um dado território? Esta questão remete o leitor para uma discussão que extrapola os limites desse estudo. Consideramos, destarte, que é necessário um acúmulo de experiências que nos permitam afiançar a veracidade desta hipótese.

Outrossim, o que está claro é que a evolução do mondovino ${ }^{8}$ e a necessidade de adaptação a um cenário cada vez competitivo e desafiador fizeram emergir uma experiência que se baseia em aspectos como a confiança, a cooperação e a capacidade de inovação de diversos atores. Um ambiente que fez surgir estruturas de governança (Conselho Regulador) que atualmente exercem suas funções para além do universo da vitivinicultura, como no caso de influir na discussão sobre o Plano Diretor dos municípios pertencentes ao recorte espacial da indicação

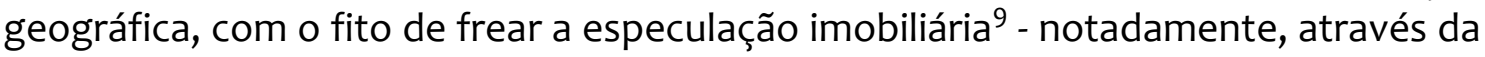
criação de condomínios de luxo na área delimitada.

A construção das antigas capelas e centros comunitários, a criação de associações comunitárias para gerir a distribuição de água, o financiamento assumido de forma compartilhada pelas famílias para a construção e extensão de redes de eletrificação e de telefonia podem ser vistos como manifestação do capital social de uma região que, obviamente, extrapola a área delimitada pela IPVV. Todavia, também é certo dizer que a estes aspectos somam-se outras questões igualmente importantes, como é a preocupação no sentido de preservar a beleza cênica de paisagens desenhadas pela mão do homem, como é o caso dos parreirais, dos caminhos rurais e dos velhos casarões de pedra.

Coincidimos com Ortega e Jeziorny (2011, p. 117) quando estes concluem:

Portanto, é cabível de se entender que, no Vale dos Vinhedos, há reciprocidade, cooperação, número de jogadores e informações a respeito da reputação de cada indivíduo. É justamente a existência de

\footnotetext{
8 “Mondovino" é o título de um grande documentário (Prêmio Festival de Cannes, 2004) realizado por Jonathan Nossiter. Aborda com muita propriedade os dilemas e os grandes conflitos do mundo do vinho, sobretudo a questão da globalização econômica a luta encarniçada entre a padronização e as estratégias de luta de atores locais por assegurar a singularidade de seus produtos.

${ }^{9}$ Curiosamente é esse um dos grandes desafios enfrentado pelos produtores de uva e vinho da região italiana de Chianti. Ver a propósito o estudo de Brunori e Rossi (2007).
} 
todas essas condições que, segundo Putnam (2000), facilita o surgimento de um bom estoque de capital social.

O caso da IPVV, que posteriormente conquistou a condição de denominação de origem ${ }^{10}$ para seus vinhos e espumantes, demonstra, de forma cabal, que a competição e a cooperação não podem ser vistas como conceitos que se opõem ou se excluem mutuamente. As empresas que se organizam em torno a um projeto desta natureza, que inclui uma plêiade de iniciativas (sobretudo, as ligadas ao enoturismo) buscam, de forma coordenada e articulada, veicular uma imagem muito positiva do próprio território, assim como uma narrativa centrada na própria identidade.

E se essa construção exprime com bastante clareza o que vimos aqui comentando, parece igualmente interesse reproduzir a pergunta feita por Durston (1998) na epígrafe de seu trabalho, qual seja: como criar capital social onde ele não existe? A resposta a esta questão remete o leitor à discussão formulada na segunda seção deste estudo. Antes de retomá-la, convém analisar a segunda experiência de indicação geográfica que elegemos neste trabalho para explorar os meandros dessa questão.

\subsection{Carne e derivados do Pampa Gaúcho da Campanha Meridional}

A introdução do gado vacum no Sul do Brasil, e nos demais países do Cone Sul, está indissoluvelmente ligada ao processo inicial de ocupação do território e ao surgimento das reduções jesuíticas durante a primeira metade do século XVII. A história dos chamados "Sete Povos Missioneiros" relata a produção de couro e de sebo como uma das atividades econômicas mais importantes desenvolvidas nas antigas reduções. Os sucessivos ataques dos bandeirantes paulistas na preação dos índios catequisados e a destruição protagonizada, durante o século XVIII, pelas duas coroas ibéricas na chamada 'guerra guaranítica', decretou o melancólico fim das reduções.

Após a expulsão dos jesuítas restou o gado, ali criado, o qual, abandonado à própria sorte, nas amplas planícies, converteu-se em imensos rebanhos selvagens, também chamados 'cimarrones'. O período subsequente corresponde ao surgimento das estâncias e das grandes invernadas, onde o gado era criado e engordado para ser comercializado dentro e fora das fronteiras do Brasil meridional.

A demanda de animais para o abate, e de animais de tiro (especialmente mulas), crescia rapidamente com a intensificação das atividades econômicas, fazendo surgir uma atividade igualmente importante, qual seja, a de tropeiro, que conduzia os rebanhos do Rio Grande do Sul até a feira de Sorocaba em São Paulo, onde os animais eram negociados.

Outra atividade econômica de vulto, ligada diretamente ao ciclo da mineração do sudeste brasileiro, corresponde à produção saladeril desenvolvida nas grandes charqueadas do Rio Grande do Sul, cujo produto (charque) era destinado à

\footnotetext{
${ }^{10}$ A condição de Denominação de Origem, seguindo o marco de indicações geográficas brasileiras, é considerada como um segundo patamar, ou seja, um estágio superior na qualidade do vinho, dado que, além da reputação consagrada, há elementos do lugar (solo, clima, etc.) que conferem singularidade e qualidade ao produto.
} 
alimentação da mão de obra escrava, sendo inclusive exportado para outros países (EUA e Cuba) para cumprir esse mesmo propósito. A imagem icônica do gaúcho, ou do "centauro dos pampas" que manejava os rebanhos, vai sendo forjada através do tempo, no Sul do Brasil e nos demais países do Prata, sobretudo por força dos sucessivos conflitos territoriais e das guerras de independência protagonizadas pelas milícias lideradas pelos grandes coronéis e pela chamada 'aristocracia do charque'.

Do ponto de vista econômico, a grande mudança vai se dar a partir da introdução das chamadas raças britânicas (Devon, Angus, Hereford), ao final do século XIX e começo do século XX que se adaptaram facilmente ao ambiente pampiano. São animais produzidos em criações extensivas, alimentados naturalmente nos pastos nativos, que guardam um padrão de excelência de uma carne que é apreciada pelos consumidores e internacionalmente reconhecida por seus atributos de qualidade. E foi por força desse intuito de diferenciação, mas sobretudo do renome, que foi sendo pensada a criação da Indicação de Procedência da Carne e derivados do Pampa Gaúcho da Campanha Meridional (doravante referida como IPCPG). Antes de entrar propriamente nessa questão, convém comentar alguns aspectos gerais.

O Bioma Pampa compreende uma superfície de aproximadamente 700 mil $\mathrm{km}^{2}$ que se estende pela Argentina, Uruguai e Brasil. A parte brasileira deste bioma está integralmente circunscrita ao Rio Grande do Sul, formada de campos nativos, compreendendo uma área de $157 \mathrm{mil} \mathrm{km}^{2}$, equivalente a quase $2 / 3$ do território gaúcho, e que abriga em seu interior grande fonte de biodiversidade animal e vegetal. Segundo Boldrini (1997), são nada menos que 400 espécies de gramíneas forrageiras e 150 espécies de leguminosas.

Paradoxalmente, o Pampa é um dos Biomas com menor percentual de área legalmente protegida em nosso país. Segundo documento do Ministério do Meio Ambiente (IBAMA, 2010), a progressiva introdução e expansão das monoculturas e de pastagens com espécies exóticas conduziram a uma rápida degradação e descaracterização das paisagens pampianas. Soma-se a isso a expansão dos grandes projetos de plantio de eucalipto - apoiados, inclusive, pelo governo estadual -, bem como, em maior ou menor medida, o crescimento da orizicultura irrigada e da sojicultura.

Nesse sentido, estimativas de perda de hábitat "dão conta de que em 2002 restavam 41,32\% da vegetação nativa do bioma Pampa, que em 2008 se havia reduzido a apenas 36,03\%" (IBAMA, 2010). É importante reter esse aspecto para entender o conteúdo da narrativa que se elabora em torno à criação da indicação de procedência.

Reconhecida oficialmente pelo INPI, em 2006, a IPCPG surgiu a partir do incentivo do SEBRAE, Serviço Nacional de Aprendizagem Rural (SENAR), da Federação de Agricultura do Estado do Rio Grande do Sul (FARSUL) e do apoio técnico prestado por pesquisadores da Universidade Federal do Rio Grande do Sul e da Embrapa Pecuária Sul.

A Criação da Associação dos Produtores do Pampa Gaúcho da Campanha Meridional (Apropampa) é fruto desse processo, que à época integrava, segundo Cerdan (2009), 66 pecuaristas, dois comerciantes e um abatedouro. O caráter extensivo desta atividade fica evidenciado quando aludimos ao tamanho dos 
estabelecimentos cujas dimensões oscilam entre aproximadamente 500 e 15.000 hectares, que tanto podem realizar o ciclo completo (cria, recria e engorda) quanto apenas a fase de terminação dos animais, desde que respeitadas determinadas condições. A área delimitada pela IPCPG é de aproximadamente 1,2 milhão de hectares, recobrindo parte dos municípios de Bagé, Aceguá, Hulha Negra, Pedras Altas, Lavras do Sul, Dom Pedrito, São Gabriel e Santana do Livramento.

O Caderno de Normas da IPCPG admite somente as raças Angus e Hereford e seus cruzamentos, sendo que a alimentação dos animais há que ser feita através de pasto nativo ou pasto nativo melhorado, podendo serem terminados em pastagens cultivadas de inverno (nativas ou exóticas) mas em regime extensivo. Outro aspecto fundamental é a exigência obrigatória de rastreabilidade dos animais, cuja idade de abate tem de ser sempre inferior a 42 meses.

O processo de construção social da qualidade é extremamente complexo e marcado por muitos conflitos na medida em que boa parte dos produtores resiste às restrições impostas no caderno de normas, sobretudo no que afeta às raças admitidas e à rastreabilidade dos animais, como assim o demonstra um de nossos entrevistados:

\begin{abstract}
Sim, mas há muita resistência do ponto de vista do que, como te posso dizer? Os produtores, pecuaristas no Rio Grande do Sul, têm muita tradição no que fazem. Desde seu avô. A princípio isso ajudaria [...]. Mas há coisas por trás que os fazem. Hoje, se mantêm na atividade porque, não sei se me explico, é muito social o tema, tá, muito comportamental. Está, todavia. Têm muitos paradigmas. E uma dessas coisas são as raças, por exemplo. Se vou dizer que para entrar na APROPAMPA tem que produzir novilhos Hereford, e teu avô tinha uma outra raça que não era Hereford... Se alguém de diz que tens que tens que mudar para Hereford para ganhar mais, tu não vai mudar a raça. Se vão produzir novilhos de cinco anos de idade, e vem à APROPAMPA, e agora te dizem que tens que produzir novilhos de dois anos, não vai produzir. Se vem à APROPAMPA e te dizem que vão ter que fazer a rastreabilidade, mas nunca fez, porque não tem controle, isso te dá mais trabalho, não vai registrar. Então, a cultura é boa, mas também é muito social o tema, me entendes? Não sei se me explico bem?"11
\end{abstract}

Tradicionalmente esta atividade econômica é marcada pelo conservadorismo dos produtores, que não obstante a introdução de diversas inovações tecnológicas, são bastante refratários à incorporação de mudanças organizacionais. De certo modo, essa tendência reflete uma cultura moldada através do tempo no tradicionalismo das antigas estâncias lideradas por grandes proprietários, cuja atuação era marcada por uma racionalidade individualista e pelo atomismo em suas relações com o mundo além das velhas mangueiras de pedra que resistem ao tempo em muitas das propriedades pampianas.

Seria este um traço atávico da alma campeira ${ }^{12}$ que desafia o tempo e as grandes transformações da sociedade da informação e da tecnologia? A resposta a

\footnotetext{
${ }^{11}$ Entrevista concedida em Bagé, no dia 26 de junho de 2012.

${ }^{12}$ Dentre as obras de José de Alencar, por muitos desconhecida, figura "O Gaúcho" (1870/1998, p. 3). Para este imortal das letras brasileiras, o aludido personagem é assim definido: "Como a árvore, são a ema, o touro, o corcel, todos os filhos bravios da savana. Nenhum ente, porém, inspira mais energicamente a alma pampa do que o homem, o gaúcho. De cada ser que povoa o deserto, toma ele o melhor; tem a velocidade da ema ou da corça; os brios do corcel e a veemência do touro.".
} 
esta questão ultrapassa os limites deste trabalho e cumpre o propósito de tão somente prospectar algumas das razões que explicam as grandes dificuldades de desenvolver projetos associativos ancorados, territorialmente, nessa parte da geografia gaúcha, sobretudo neste setor da atividade econômica.

Por outro lado, as relações com os frigoríficos são historicamente marcadas por conflitos, sendo recorrentes as falências destas empresas, sejam elas de natureza eminentemente privada ou mesmo cooperativada. Trata-se de um setor que reunia, à época da fase de campo, 121 empresas com um faturamento que oscilava em torno de 2 bilhões de reais. O caso da IPCPG mostra as contradições de um processo de organização que pouco tem avançado, se temos em mente que atualmente inexiste produção de carne comercializada sob este selo ou condição.

A Marfrig Alimentos consiste no principal destino da produção bovina de qualidade (com rastreabilidade), sendo a primeira indústria do ramo a adotar as principais modalidades internacionais de certificações. Todavia, o contato com a realidade mostrou que a comercialização de carne com indicação de procedência é ainda uma quimera. Esta empresa, que a seu tempo firmou parceria com a Apropampa, valoriza a raça animal (sobretudo Aberdeen Angus e Hereford) com um preço prêmio correspondente.

Mostrar a importância da pecuária extensiva na preservação ambiental foi assumido como parte de um discurso mais amplo que marcou a aproximação com uma organização não governamental (ONG) - La Alianza del Pastizal - que integra pecuaristas e atores sociais da cadeia de carnes da Argentina, Uruguai, Brasil e Paraguai. Em linhas gerais, trata-se de defender o papel desta atividade na conservação da biodiversidade ${ }^{13}$, especialmente quando são evidentes, como vimos anteriormente, as ameaças de degradação do Bioma Pampa brasileiro.

Mas que motivos, concretamente, existem para que a proposta da IPCPG não consiga avançar em seus propósitos? Por que razão este sinal distintivo é absolutamente desconhecido pelos consumidores gaúchos e brasileiros? Na seção precedente vimos que a região do Vale dos Vinhedos dispõe dos serviços prestados pela Embrapa Uva e Vinho de Bento Gonçalves, que desempenhou um papel estratégico na criação da IPVV. Do mesmo modo, a região que cobre a área delimitada pela IPCPG conta com uma instituição tradicional de pesquisa - a Embrapa Pecuária Sul - sediada em Bagé, dedicada à produção de conhecimento e de inovação neste âmbito. Por que razão as duas IGs vivenciam trajetórias tão distintas? As singularidades relativas à pecuária extensiva, enquanto atividade produtiva, são suficientes para explicar as diferenças entre estas duas estratégias de diferenciação de produtos agroalimentares? A próxima subseção busca respostas a estas questões.

\subsubsection{O Capital Social na região da Apropampa}

A orientação primordial que moveu a criação da Apropampa e da própria IPCPG era a de diferenciar-se de outros sistemas de produção, sobretudo do que é praticado em outras regiões do país como o Brasil central, onde predominam os

\footnotetext{
${ }^{13}$ Esta ONG se vincula a outras organizações do gênero, conhecidas internacionalmente, como é o caso da BirdLife International. Ver a propósito: http://www.pastizalesdelconosur.org/index.php/es/viencuentro-de-ganaderos-de-pastizales-naturales-del-cono-sur.html
} 
sistemas confinados de criação de raças zebuínas, em que a produção visa atender, fundamentalmente, aos consumidores menos exigentes e às grandes superfícies de varejo. A marca das raças britânicas, indubitavelmente, é a qualidade de um produto obtido em condições muito especiais, potencialmente apto à exportação através da incorporação da rastreabilidade e de convenções de qualidade. Mas o quadro atual deste processo de organização dista muito desse propósito no caso da IPCPG.

Nesse sentido, no trecho a seguir consta a avaliação feita por pesquisador que se dedicou ao estudo da questão, o qual descreve um cenário da IPCPG que pouco se modificou através do tempo. No contato com a realidade chegamos a conclusões idênticas ao que alude o autor quando este afirma:

\begin{abstract}
La puesta en mercado se caracteriza por la presencia de dos distribuidores. El primero es um comercio que ofrece especialidades, situado en Porto Alegre, capital del Estado de Rio Grande do Sul. El segundo es un comercio de la cadena de supermercados Peruzo, localizado en Bagé. A pesar del interés que despierta este proyecto en los actores locales involucrados, la relevancia económica del mismo permanece marginal. De hecho, hasta el momento la faena se sitúa en unos 50 animales por semana (promedio para el año 2007). Por el momento, la escasa relevancia del volumen faenado no alcanza a generar expectativa en el mercado nacional y menos aún pensar em una proyección internacional. (CHAMPREDONDE et al, 2008, p. 12)
\end{abstract}

Não é preciso muito esforço para apontar as flagrantes diferenças existentes entre ambos os territórios aqui cotejados do ponto de vista da densidade institucional. No caso da carne, a busca pela singularização de um produto de qualidade esbarra na ausência de estruturas de governança que contemplem o conjunto de atores desta cadeia produtiva em torno a uma ideia guia que fica totalmente à mercê das determinações de um único frigorífico. A experiência mundial demonstra que uma indicação geográfica representa uma ferramenta coletiva de promoção de um produto portador de identidade e de tipicidade. Todavia, é impossível pensar num processo de construção social da qualidade dessa envergadura que renuncie, ao fim e ao cabo, aos princípios do associativismo, da confiança e da coesão social.

A fragilidade deste processo aparece claramente evidenciada no fato de que, não obstante ser esta uma atividade de importância capital para a economia e para a identidade regional, detentora de consagrada notoriedade e reputação, a Apropampa nem sequer dispõe de um espaço próprio para o desenvolvimento de suas atividades, como bem ilustra um de nossos entrevistados:

\footnotetext{
$\mathrm{Na}$ medida que nós participamos do conselho regulador, a Embrapa oferece o próprio local de reuniões pros conselhos da Apropampa se reunirem aqui. Como um ponto central, como a Apropampa não tem sede própria, né, então, coisas pequenas, como essa, até a discussão na participação dos processos, da ajuda, no desenvolvimento... Agora mesmo nós estamos discutindo a retomada do produto ao consumidor, porque houve uma troca do frigorifico que fazia o abate, dos donos do frigorífico.[...]. Antes era outro proprietário, [...] a planta frigorifico é a mesma, mas em função dessa troca houve um processo de quebra no
} 
fornecimento da carne ao consumidor. Então, agora nós estamos retomando as negociações pra começar... ${ }^{14}$

O depoimento acima mostra que, transcorridos mais de seis anos desde a sua criação, a IPCPG é ainda um projeto em construção. A natureza extensiva da atividade, com seus desdobramentos negativos sobre a interação dos atores sociais, não pode ser vista como a causa única e exclusiva do insucesso dessa iniciativa. As causas são bem mais profundas e remetem para uma discussão mais ampla que envolve o capital social dos territórios. Nesse sentido, convergimos para a posição assumida por um autor que exprime, de forma magistral, esse mesmo entendimento, quando se refere à Itália:

\begin{abstract}
Diante de novos problemas que requerem solução coletiva, homens e mulheres de toda parte vão buscar soluções no seu próprio passado. Os cidadãos das comunidades cívicas descobrem em sua história exemplos de relações horizontais bem-sucedidas, enquanto os cidadãos das regiões menos cívicas encontram, quando muito, exemplos de suplicação vertical. (PUTNAM, 2000, p. 184).
\end{abstract}

Na visão crítica exposta por Champredonde et al. (2008), ao analisarem o projeto de criação da IPCPG, outros aspectos importantes são incorporados à discussão, quando referem que os critérios adotados na construção do caderno de normas refletem muito mais as exigências do mercado, do que propriamente uma tradução fiel das práticas predominantes no universo de explorações agropecuárias da Campanha Meridional. O volume inexpressivo de carne vendida com o selo da IPCPG exprime, não somente a incapacidade de cumprir o próprio protocolo, mas também o escasso retorno que pode representar em termos monetários para os criadores.

O fato de ter sido uma iniciativa que envolve pecuaristas detentores de extensas áreas não pode ocultar o fato de que também existem pequenos proprietários, cujo número supera ao dos grandes estancieiros. Os pequenos criadores vivem da produção de gado e de ovinos e foram 'naturalmente' excluídos de participar desse projeto. Não obstante, são claros e evidentes os indícios da escassa capacidade de articulação daqueles que um dia imaginaram levar adiante esta iniciativa. Nem os objetivos mercadológicos foram atendidos, muito menos a ideia de converter esse processo numa estratégia incrustada no território a partir de alianças que fizessem expandir as oportunidades para além das próprias fronteiras.

Quais foram os responsáveis por liderar a iniciativa de criação da IPCPG? O depoimento satisfaz essa indagação de forma muito cristalina:

Não era uma ideia dos produtores. Não foram os produtores que identificaram que a indicação geográfica poderia ser uma boa coisa para eles. Foi o SEBRAE, foi a ideia do professor $X$, foi a ideia de alguém da Embrapa, entendes? Não surgiu dos produtores. Essa é uma questão importante, muito importante. E por aí passa muitas coisas que hoje ocorrem dentro da associação [...] Há muita dificuldades ainda que não foram superadas. Falta muita organização interna. Falta envolver mais os produtores, porque nasceu dessa forma. Havia uma consultoria para isso... Creio que, hoje é JK, secretário executivo, lá atrás havia uma outra

\footnotetext{
${ }^{14}$ Entrevista concedida em Bagé, no dia 25 de junho de 2012.
} 
pessoa, que o SEBRAE reportava recursos, que pagava. E, bom, a associação nasceu da ideia de uma indicação geográfica para os produtores, tinham várias coisas no objetivo ${ }^{15}$.

O fato de não haver sido um projeto capitaneado pelos próprios pecuaristas não pode ser visto como um fato necessariamente impeditivo para que a IPCPG pudesse avançar, tal como tantas outras experiências do gênero. Sabemos que é este, precisamente, um dos papeis cruciais reservados às diversas agências e instituições identificadas com o desenvolvimento dos territórios, como é o caso do SEBRAE, da Embrapa e das universidades. O problema é que existem obstáculos bastante grandes a serem transpostos nessa região e nesse tipo de atividade socioprodutiva, sendo que tais dificuldades revelam que nem sempre tradição e inovação andam de mãos dadas. O exemplo em epígrafe mostra que podem, inclusive, estar em franca oposição.

Em suma, de um lado, tem-se a frágil capacidade de articulação dos pequenos, médios e grandes criadores de gado dessa região, de outro, consta o enorme protagonismo de grandes conglomerados cujo poder econômico e político alcança proporções inusitadas no contexto de uma economia totalmente globalizada. A criação de uma marca coletiva ${ }^{16}$ poderia ter sido um caminho mais promissor para fomentar a cooperação entre os atores sociais do território em lugar da insistência em um projeto de criação de uma indicação geográfica que, concretamente, se desintegrou sem jamais tornar-se realidade.

A recente operação deflagrada pela Polícia Federal brasileira, intitulada "Carne Fraca" evidenciou não somente as imbricações desse setor com as estruturas de poder do país, mas especialmente os sofisticados mecanismos de proteção e de favorecimento dos próprios interesses.

\section{Conclusões}

$\mathrm{Na}$ realização dessa pesquisa lançamos mão de duas ferramentas interpretativas que consideramos capazes de iluminar o debate em torno ao potencial dos sinais distintivos de qualidade e da construção de itinerários de diferenciação da produção agroalimentar em prol do desenvolvimento dos territórios rurais. Deixamos claro o quão relevante pode ser esse caminho naquelas regiões marcadas por uma escassa densidade do tecido social e produtivo e por uma forte tradição de verticalidade nas relações políticas e socioculturais.

O caso do Vale dos Vinhedos é emblemático na medida em que mostra como uma organização, surgida em meio a uma grande crise que afetava a vitivinicultura brasileira durante os anos 1990, foi inicialmente responsável por imprimir uma nova dinâmica, ao organizar, todo um setor, mediante a criação de uma associação, cujo processo de articulação culminou, entre outros aspectos, na constituição da primeira Indicação Geográfica do Brasil. Entrementes, ao longo do tempo, a

\footnotetext{
${ }^{15}$ Entrevista concedida em Bagé, no dia 25 de junho de 2012. Omitimos quaisquer informações que pudessem revelar a identidade das pessoas entrevistadas ou citadas.

${ }^{16}$ Essa foi a opção tomada por pequenos criadores situados dentro do que se veio a chamar "território do Alto Camaquã", pertencente à região sul do Rio Grande do Sul. Trata-se de projeto liderado pela Embrapa Pecuária Sul (Bagé, RS). Sobre essa experiência, ver a propósito MATTE et al (2016).
} 
Aprovale passa a incorporar outros papeis, inclusive o de converter-se no que os estudiosos do tema (LANGREO e GARCÍA, 1995; ORTEGA, 2005) denominam de interprofissional, qual seja, uma organização que congrega, em torno de si, os interesses dos diversos atores (agricultores, vinicultores, empresários, etc.) de uma cadeia de valor, referida a um produto, que é a marca insofismável da italianidade.

O horizonte de atuação da Aprovale se depara hoje com outros desafios como é a questão do Plano Diretor dos municípios frente aos efeitos produzidos pela espiral especulativa das terras, que acomete a região onde se acha delimitada a indicação geográfica. Por outro lado, a recente criação da Denominação de Origem Vale dos Vinhedos traz consigo outras implicações, como é precisamente o caso das restrições com relação à origem da uva, quantidade colhida por planta e outros requisitos que fazem parte de um novo caderno de normas ainda mais rigoroso que o da IPVV, assim como, de novas convenções de qualidade.

Sob um ambiente de incertezas, como é precisamente o que estamos vivendo, e que atinge implacavelmente os mais recônditos âmbitos da vida social, econômica e cultural, torna-se imperativo que os atores sociais estabeleçam uma estrutura de governança que aglutine em torno de si o conjunto de demandas e interesses das forças vivas do território. A ideia guia é forjada a partir de uma identidade compartilhada e de um ambiente institucional que impele à cooperação.

Por outra parte, o caso da IPCPG ilustra quão complexa é a missão de criar capital social num ambiente em que praticamente inexiste a predisposição à cooperação, à inovação e à coesão social. Referimo-nos a uma região que possui uma identidade calcada na imagem icônica do gaúcho, na qualidade de um produto (a carne e seus derivados) e na beleza de suas paisagens, mas que, paradoxalmente, enfrenta grandes resistências para ultrapassar as fronteiras do atomismo dos produtores e a desarticulação dos atores do território. Concretamente, há limites para converter-se numa comunidade cívica, exaltada nos estudos sobre capital social, especialmente porque os agentes se mostram incapazes de 'erigir pontes', parafraseando Putnam (2000), e de interagir com outros atores sociais, para além da porteira de suas estâncias.

Os exemplos aqui confrontados e a noção de capital social nos convidam a refletir sobre a importância dos processos de cooperação. Remetem-nos à eterna discussão sobre a natureza hobbesiana de uma sociedade regida agora pelo império da globalização e pela diluição das fronteiras físicas e identitárias. As indicaçõos geográficas podem converter-se, decididamente, num instrumento de desenvolvimento territorial, sempre e quando outras condições e circunstâncias estejam presentes, sobretudo quando se pensa na necessidade de constituir um sujeito coletivo em torno a uma ideia guia que expresse a capacidade de articulação dos vetores dinâmicos do território. Portanto, uma das principais lições que se pode extrair das duas experiências aqui cotejadas, é no sentido de reafirmar que a criação de uma indicação geográfica há que ser vista, decididamente, não como o destino final de um processo, mas como ponto de partida numa longa caminhada de construção social da qualidade e da diferenciação. 


\section{AGRADECIMENTOS}

Os autores agradecem ao Conselho Nacional de Desenvolvimento Científico e Tecnológico (CNPq) o apoio recebido através da concessão de produtividade ao primeiro autor (processo $\mathrm{n}^{\circ}$ 305086/2018-9). Registram também o apoio da Coordenação de Aperfeiçoamento de Pessoal de Nível Superior (CAPES), pela Bolsa de Professor Visitante Sênior (PRINT-CAPES PROGRAM) ao primeiro autor (processo $n^{\circ} 88887.363956 / 2019-00$ ) e Bolsa de Professor Visitante Júnior para o terceiro autor (processo $\left.\mathrm{n}^{\circ} 88887.363881 / 2019-00\right)$ ). O segundo autor foi agraciado com bolsa PNPD Capes durante os anos 2013-2018. Este trabalho foi concluído durante missão científica (2019-2020) realizada junto ao "Instituto de Estudios Sociales Avanzados" (Córdoba), ligado ao "Consejo Superior de Investigaciones Científicas de Espanha”, ao qual estendem os mais sinceros agradecimentos.

\section{REFERÊNCIAS}

ABRAMOVAY, R. Para una teoría de los estudios territoriales. In: MANZANAL, M.; NEIMAN, G.; LATTUADA, M. (Org.) Desarrollo Rural. Organizaciones, instituciones y territorios. Ciccus: Buenos Aires, p.51-70, 2006.

ABRAMOVAY, R. O futuro das regiões rurais. Porto Alegre: Ed. da UFRGS, 2003.

ALENCAR, J. O Gaúcho. Disponível em:

http://www.dominiopublico.gov.br/pesquisa/DetalheObraForm.do?select_action=\& co_obra=1842 Acesso em: 22 set. 2012.

ALIANZA DEL PASTIZAL. Disponível em: http://www.pastizalesdelconosur.org/ Acesso em: 8 out. 2012.

BOLDRINI, I. I. Campos do Rio Grande do Sul: Caracterização fisionômica e problemática ocupacional. Boletim do Instituto de Biociências, n. 56, 39p., 1997.

BRASIL Instituto Brasileiro de Meio Ambiente. Relatório Técnico do Monitoramento do Desmate do Bioma Pampa. Disponível em:

http://www.mma.gov.br/estruturas/sbf_chm_rbbio/_arquivos/relatorio_tecnico_mo nitoramento_desmate_bioma_pampa_72.pdf Acesso em: 8 out. 2012.

BRASIL. Presidência da República. LEI N 9.279, DE 14 DE MAIO DE 1996, Regula direitos e obrigações relativos à propriedade industrial. Disponível em: http://www.planalto.gov.br/ccivil_03/leis/L9279.htm Acesso em: 8 out. 2012.

BRUNORI, G.; ROSSI, A. Differentiating countryside: Social representations and governance patterns in rural areas with high social density: The case of Chianti, Italy. Journal of Rural Studies, v.23, p.183-205, 2007. 
CERDAN, C. Valorização dos produtos de origem e do patrimônio dos territórios rurais no sul do Brasil: Contribuição para o desenvolvimento territorial sustentável. Política \& Sociedade, n.14, p.277-299, 2009.

CHAMPREDONDE, M.; CASABIANCA, F., VITROLLES, D.; CERDAN C. La Pampa como indicación geográfica para diferenciar carnes vacunas en Argentina y en Brasil: motivaciones de los actores locales, limitantes para su implementación. In: CONGRESO INTERNACIONAL DE LA RED SIAL, 5, Mar del Plata 27 al 31 de octubre de 2008, Anales..., 2008.

COLEMAN, J. Foundations of social theory. Cambridge, Londres: The Belknap Press of Harvard University Press, 1990.

DURSTON, J. Building social capital in rural communities (where it doesn't exist). Theoretical and policy implications of peasant empowerment. In: CHIQUIMULA, Guatemala - Latin American Studies Association (LASA), The Palmer House Hilton, Chicago, II, September, p. 24-26, 1998.

FAVARETO, A. Paradigmas do desenvolvimento rural em questão. São Paulo, Fapesp, Ed. Iglu. 2007.

FAVARETO, A. A abordagem territorial do desenvolvimento rural - mudança institucional ou "inovação por adição". Estudos Avançados, v. 24, n 68, p.298-319, 2010.

GAIGER, L. I. A práxis coletiva dos sem-terra rumo à unidade ou à heterogeneidade cultural? Cadernos de Sociologia, n 6, p. 177-203, 1994.

GARRIDO, F.; MOYANO ESTRADA, E. Capital social y desarrollo en zonas rurales: un análisis de los programas Leader II y Proder en Andalucía. Revista Internacional de Sociología, v. 60, $\mathrm{n}^{\circ}$ 33, p.67-96, 2002.

GOLLO, S.S. Delineamento e aplicação de Framework para análise das inovações numa perspectiva de processo interativo: estudo de caso da indicação de procedência vale dos vinhedos - Serra Gaúcha/RS. Teoria e evidência econômica, v.14, p.247-277, 2006.

GRANOVETTER, M. The old and the new Economic Sociology: a history and an agenda. In: FRIEDLAND, R. \& ROBERTSON, A.F. (Eds). Beyond the marketplace: rethinking economy and society. New York: Aldine de Gruyter, , p. 89-112, 1990.

GRANOVETTER, M. The Strength of Weak Ties. American Journal of Sociology, Vol. 78, No. 6, May, p. 1360-1380, 1973.

GRAZIANO DA SILVA, J. A modernização dolorosa. Rio de Janeiro: Zahar, 1982. 192p. 
GUIMARÃES, A. P. O complexo agroindustrial. In: GUIMARÃES, A.P. A crise agrária. Rio de Janeiro, Paz e Terra, p. 113-149, 1978.

HERVIEU, B. Los Campos del Futuro. Madrid: Ed. MAPA, 1996.

KAYSER, B.; BRUN, A.; CAVAILLÈS, J.; LACOMBE, P. Pour une ruralité choisie. Paris: Datar Éditions de l’Aube, 1994.

MACHADO, N. M. C. Karl Polanyi e a nova sociologia econômica: notas sobre o conceito de (dis) embeddedness. Revista Crítica de Ciências Sociais, v.90, setembro, p.71-94, 2010.

MATTE, Alessandra et al. Mercado de cadeias curtas na pecuária familiar: um processo de relocalização no território Alto Camaquã no Sul do Rio Grande do Sul/Brasil. Redes (St. Cruz Sul, Online), Santa Cruz do Sul, v. 21, n. 3, p. 137-158, set. 2016. ISSN 1982-6745. Disponível em:

https://online.unisc.br/seer/index.php/redes/article/view/5578 Acesso em: $21 \mathrm{fev}$ 2020. doi:https://doi.org/10.17058/redes.v21i3.5578.

NIEDERLE, P. A. Controvérsias sobre a noção de indicações geográficas enquanto instrumento de desenvolvimento territorial: a experiência do Vale dos Vinhedos em questão. In: $47^{\circ}$ Congresso Brasileiro de Economia, Administração e Sociologia Rural, Anais..., Porto Alegre: SOBER, 2009.

ORTEGA, A. C. Agronegócios e representação de interesses no Brasil. Uberlândia: Edufu, 2005.

ORTEGA, A. C.; JEZIORNY, D. L. Vinho e Território. A experiência do Vale dos Vinhedos. Campinas: Alínea, 2011. 200p.

PUTNAM, R. D. Comunidade e democracia - A experiência da Itália moderna. Rio de Janeiro: Fundação Getúlio Vargas Editora, 2000.

SACCO DOS ANJOS, F.; CALDAS, N. V. Construindo a segurança alimentar? A experiência recente dos CONSADs no Brasil Meridional. RESR, Rio de Janeiro, vol. $45, n^{\circ} 03$, p. 645-673, 2007.

SILVA, F.N. da; SACCO DOS ANJOS, F.; CALDAS, N.V.; POLLNOW, G.E. Desafios à institucionalização das indicações geográficas no Brasil. Desenvolvimento Regional em debate, Canoinhas, v.2, n.2, p.31-44, 2012.

TEDESCO, J. C. Contratualização e racionalidade familiar. In: TEDESCO, J.C. (Comp.) Agricultura familiar: realidades e perspectivas, Passo Fundo, EDIUPF, p. 107-145, 1999.

TONIETTO, J. Experiências de desenvolvimento de indicações geográficas: vinhos da indicação de procedência Vale dos Vinhedos. In: LAGES, V.; LAGARES, L.; BRAGA, C. 
L. (Orgs.), Valorização de produtos com diferencial de qualidade e identidade: indicações geográficas e certificações para competitividade nos negócios, Brasília: Sebrae, p.155-176, 2006.

VEIGA, J. E. A face rural do desenvolvimento - natureza, território e agricultura. Porto Alegre: Ed. UFRGS, 2000.

Flavio Sacco dos Anjos. Departamento de Ciências Sociais Agrárias, Doutor em Sociologia, Pós-Doutorado em Antropologia pela Universidade de Sevilha, PósDoutor em Sociologia pela Universidade da Calábria.saccodosanjos@gmail.com

Fernanda Novo da Silva. Bolsista PNPD CAPES. Universidade Federal de Pelotas. fernandanovo@gmail.com

Nádia Velleda Caldas. Programa de Pós-Graduação em Sistemas de Produção Agrícola Familiar da UFPel. Programa de Pós-Graduação em Desenvolvimento Territorial da UFPel. Pós-Doutorado pela Universidade da Calábria, Itália. velleda.nadia@gmail.com

Como citar: DOS ANJOS, Flávio Sacco; DA SILVA, Fernanda Novo; CALDAS, Nádia Velleda. Indicações geográficas, capital social e desenvolvimento territorial. Redes (St. Cruz Sul, Online), Santa Cruz do Sul, v. 25, n. 2, p. 721-743, abr. 2020. ISSN 1982-6745. Disponível em: https://online.unisc.br/seer/index.php/redes/article/view/9636 Acesso em: 15 maio 2020. doi: https://doi.org/10.17058/redes.v25i2.9636

\section{CONTRIBUIÇÃO DE CADA AUTOR}

a. Fundamentação teórico-conceitual e problematização: Flavio Sacco dos Anjos, Fernanda Novo da Silva e Nádia Velleda Caldas

b. Pesquisa de dados e análise estatística: Flavio Sacco dos Anjos, Fernanda Novo da Silva e Nádia Velleda Caldas

c. Elaboração de figuras e tabelas: Flavio Sacco dos Anjos, Fernanda Novo da Silva e Nádia Velleda Caldas

d. Fotos: NÃO SE APLICA.

e. Elaboração e redação do texto: Flavio Sacco dos Anjos, Fernanda Novo da Silva e Nádia Velleda Caldas

f. Seleção das referências bibliográficas: Flavio Sacco dos Anjos, Fernanda Novo da Silva e Nádia Velleda Caldas

Fontes de financiamento: CNPq, FAPERGS e CAPES. 